\title{
REFLEXÕES SOBRE O TRABALHO DE TRADUÇÃO E INTERPRETAÇÃO EM LÍNGUAS DE SINAIS COMO PRÁTICA ÉTICA E POLÍTICA NO CUIDADO DE SI
}

\author{
Lucyenne Matos da Costa Vieira-Machado* \\ Universidade Federal do Espírito Santo
}

Jefferson Bruno Moreira Santana**

Universidade Federal do Espírito Santo

\begin{abstract}
* Doutora (2012) e Mestre (2007) em Educação pelo Programa de Pós-graduação em Educação da Universidade Federal do Espírito Santo (PPGE- UFES). Pós-doutora em Educação (2015) pelo Programa de Pós-graduação em Educação da Universidade Vale do Rio dos Sinos (Unisinos). Graduada em Pedagogia pela Universidade Federal do Espírito Santo, na qual atualmente é professora Adjunta I da disciplina Língua Brasileira de Sinais (Libras) no Centro de Ciências da Saúde (CCS), curso de Fonoaudiologia. Professora e orientadora de mestrado do curso de Pós-graduação em Educação (PPGE/UFES) na linha Diversidade e Práticas Educacionais Inclusivas. Coordenadora do Grupo de Pesquisa em Libras e Educação de Surdos (GIPLES/CNPq-UFES) e pesquisadora do Grupo de Estudos e Pesquisas em Inclusão (GEPI/CNPq-UNISINOS). Tem experiência na área de Educação e Educação Especial (com ênfase em Educação de Surdos), atuando, principalmente, nos seguintes temas: Inclusão, Acessibilidade, Subjetivação, Libras, Surdos, Estudos Surdos. Espírito Santo, Bahia, Brasil. E-mails: luczarina@ yahoo.com.br/ lucyenne.machado@ufes.br

** Mestre (2010) em Literatura pela Universidade Federal de Santa Catarina (UFSC) e graduado (2007) em Letras pela Universidade Federal do Espírito Santo (UFES). Atualmente, é professor-assistente na Universidade Federal do Espírito Santo. Tem experiência na área de Letras, com ênfase em Língua Portuguesa, atuando, principalmente, nos seguintes temas: tradução em Libras, tradução cultural, tradução literária, estudos da interpretação, performance e corpo. Espírito Santo, Bahia, Brasil. E-mail: jefferson_lsb@yahoo.com.br
\end{abstract}


Resumo: Refletir sobre o trabalho do tradutor e intérprete de línguas de sinais (TILS) como prática ética e política no cuidado de si constitui-se uma questão urgente em nosso tempo e é o objetivo central deste texto. Com a constituição de saberes acadêmicos e especializados dos estudos da tradução e interpretação das línguas de sinais e sua afiliação com o campo dos Estudos da Tradução, o deslocamento do papel do TILS é emergente. Além da introdução e das considerações finais, o texto será dividido em três partes. Na primeira, serão abordadas as pesquisas e as questões políticas que hoje emergem acerca do TILS empreendidas pelos dispositivos governamentais, com o objetivo de localizar a relevância deste texto, que é discutir a ética como prática de vida para além de questões prescritivas. Na segunda parte do texto, serão problematizadas, atravessadas por uma inspiração foucaultiana, as questões que permeiam a prática do TILS a partir da compreensão de sua função como intelectual específico e a responsabilidade que assume na elaboração de sua própria subjetividade. Por fim, na terceira parte deste trabalho, será discutido o compromisso com o ato tradutório na relação com o texto e com o outro como posição ética. Palavras-chave: Ética. Intelectual específico. TILS. Cuidado de si.

\title{
THOUGHTS ABOUT THE WORK OF TRANSLATION AND INTERPRETATION IN SIGN LANGUAGE AS ETHICAL AND POLITICAL PRACTICE IN SELF CARE
}

\begin{abstract}
Think about the work of sign language translator and interpreter (SLTI) as ethical and political practice in self care constitutes an urgent question in our time and it is the main objective of this paper. With this constitution of academic and specialized knowledge of the translation and interpretation studies of sign language e its affiliation with the Translation Studies field, the displacement of the SLTI is emergent. Besides the introduction and final conclusions, the text will be divided in three parts. The first part, we will discuss about research and political questions that emerges about the SLTI. Those are undertaken by government devices with the objective to locate the relevance of the purpose of this text that is beyond prescriptive and descriptive ethics and discuss it as practical life. In the second part of the text it will be problematized, questions, inspired by Foucault, that penetrates the ethical practice of the SLTI starting from the comprehension of its function as intellectual in the area and its responsibility that asumes in the elaboration of its own subjectivity. To finish, in the last part of this paper, the commitment with the translation and the text and with the other as an ethical position adopted.
\end{abstract}

Keywords: Ethics, Intellectual in the area, SLTI, Self Care. 
A técnica tem má fama; pode parecer destituída de alma. Mas não é assim que é vista pelas pessoas que adquirem nas mãos um alto grau de capacitação. Para elas, a técnica estará sempre intimamente ligada à expressão. [...] De todos os membros do corpo humano, é ela dotada de maior variedade de movimentos, que podem ser controlados como bem queremos. A ciência tenta demonstrar como esses movimentos, aliados ao tato e às diferentes maneiras de segurar com as mãos, afetam nossa maneira de pensar.

Richard Sennett

\section{Introdução}

A partir do trecho supracitado do livro "O Artífice”, de Richard Sennett (2013), este texto tem, como objetivo principal, buscar outras possibilidades de refletir sobre o trabalho do tradutor e do intérprete de línguas de sinais (TILS). Portanto, o desafio é pensar sobre a ação laboral da tradução como prática ética e estética na criação de um modo de vida. Na esteira de Sennett (2013), pode-se afirmar que, se pelo menos entendermos como são feitas as coisas, podemos alcançar uma vida material mais humana.

Partindo da ideia de que o trabalho dá possibilidades para tornar o homem criador de si, tornar-se um artífice inquieto é condição para escrever o que se segue. Para tal investimento, este ensaio propõe-se a discutir sobre as questões éticas que atravessam as práticas desse profissional com um único pressuposto aqui definido: de que se trata de um intelectual específico nos termos de Foucault (2005).

Neste trabalho, as questões éticas estão atravessadas por um modo de vida. Para pensar sobre a constituição de um êthos na tarefa do TILS, este texto vai dar as costas, por ora, a uma perspectiva de uma ética prescritiva que trate de modos de fazer. Não que 
as prescrições sejam menos importantes ou mais desqualificadas. Mas o objetivo desta iniciativa é pensar outras possibilidades de discussão sobre o trabalho do TILS como modo de vida (êthos) a partir das teorizações de inspiração foucaultiana.

De acordo com Hattim e Munday (2004), os Estudos da Tradução estabelecem interfaces com teorizações de diferentes disciplinas. No mapa realizado pelos autores ${ }^{1}$, pode-se perceber os campos teóricos envolvidos tendo como objeto de estudo a tradução. Ao verificar o mapa, percebe-se a afiliação deste trabalho com as teorizações filosóficas baseadas na hermenêutica pós-estruturalista e desconstrucionista.

Assim, em um primeiro momento, será explanada, no texto que se segue, uma discussão sobre o trabalho do tradutor e do intérprete de línguas de sinais como prática de vida activa e, portanto eminentemente política. Este conteúdo será situado nas produções que discutem as questões éticas do trabalho do TILS e a localização teórica e política deste trabalho. Em seguida, será abordada a tarefa do TILS como intelectual específico e sua relação com a verdade em uma prática ética, política e estética do trabalho do tradutor como prática de cuidado de si.

A fim de continuar as argumentações, o texto passará a discutir as práticas de cuidado de si como atitude, constituindo, assim, um espaço pedagógico com o outro por meio do trabalho tradutório em uma perspectiva benjaminiana. Nas considerações finais, apontarse-á para o deslocamento da perspectiva do trabalho do TILS em consideração à abordagem filosófica e política da discussão da ética do trabalho do tradutor e intérprete como modo de vida.

\section{Abrindo a caixa de Pandora: questões políticas e o trabalho de tradução e interpretação em Línguas de Sinais no nosso tempo}

Segundo Arendt (2013, p. 21), “a política baseia-se na pluralidade dos homens" e a ação política só é possível com os outros no 
exercício de uma prática de vida activa. A condição humana, para a autora, reside nos conceitos das três atividades fundamentais na constituição de uma vida activa: trabalho, obra e ação.

Para Arendt (2014), o trabalho assegura a sobrevivência não apenas do indivíduo, mas da espécie. A obra - ou o artefato humano -, por sua vez, garante uma historicidade da espécie e seu espaço de existência que é o mundano. Por fim, a ação é a única que não necessita de meios materiais, pois está pautada apenas na relação dos homens entre si.

Não é possível pensar a prática política como prática de vida activa sem levar em conta a relação entre essas três noções enquanto condição humana. E, tomando aqui a ação como atividade essencialmente política, pode-se afirmar que ela "[...] se empenha em fundar e preservar corpos políticos, cria a condição [...] para a história" (ARENDT, 2014, p. 11).

Olhar, em nosso tempo, o trabalho do tradutor e intérprete de Língua de Sinais como uma prática de uma vida activa não é, em hipótese alguma, desvinculá-lo de uma ação política. E esse exercício de pensamento pode originar um medo racional de Pandora.

Deusa da invenção, Pandora foi enviada à Terra por Zeus como um presente da ira dos deuses pelo castigo da transgressão de Prometeu $^{2}$. Pandora portava uma caixa de maravilhas que despertava curiosidade. Porém, no mito grego, ao ser aberta, espalha dores e males entre os homens.

Destarte, acreditar que a ação de abrir a caixa possa ser um ato neutro relativo à admiração e à curiosidade despertadas pelo desconhecido é quase ingênuo e não condiz com a ação política da vida activa, que é condição de humanidade. E, assim, na esteira de Arendt (2014), o ato de abrir a caixa de Pandora pode tornar o seu conteúdo menos ameaçador quando o trabalho do tradutor e intérprete de línguas de sinais qualifica-se como um modo de vida activa e, portanto, eminentemente político.

Na temática de políticas de tradução/interpretação no âmbito das línguas minoritárias, em especial, da Língua Brasileira de Sinais (Libras), pode-se enfatizar as legislações como um incentivo 
à qualidade de ensino de estudantes surdos e à formação de tradutores e intérpretes, em especial a Lei $\mathrm{n}^{\mathrm{0}} 10.098 / 00$, que aborda o direito dos surdos ao acesso à comunicação em Libras, e a Lei ${ }^{0}$ 10.436/02, a qual oficializa a Libras como a língua das comunidades surdas do Brasil. Vale a pena ressaltar, ainda, o Decreto $\mathrm{n}^{\mathrm{o}}$ $5.626 / 05$, que regulamenta as duas leis citadas anteriormente e leva a ações de formação de professores de Libras, de tradutores e de intérpretes, e a Lei $\mathrm{n}^{\mathrm{o}} 12.319 / 10$, que regulamenta a profissão do tradutor e intérprete de Libras.

Esses dispositivos governamentais que apresentam demandas educacionais, linguísticas e tradutórias se tornam um fio condutor para a elaboração de produções na área da tradução e interpretação, bem como ações de formação. Como exemplo, pode-se citar dicionários bilíngues, glossários, traduções literárias, curso de graduação em nível de licenciatura e bacharelado (formação de professores e de tradutores e intérpretes), materiais didáticos e produções acadêmicas - como teses e dissertações na área dos Estudos da Tradução e da Interpretação, da Literatura, da Linguística, da Educação, entre outras - e eventos específicos da área.

Desse modo, com o mapeamento de pesquisas nesses campos, realizado por alguns estudiosos da área, como Santos (2013), Rodrigues (2013) e Pereira (2010), verifica-se uma significativa produção acadêmica sobre questões relacionadas à tradução e à interpretação em língua de sinais nos programas de pós-graduação stricto sensu de 1995 a 2014.

Em nível de mestrado e doutorado, foram encontradas, durante o levantamento a partir dos trabalhos anteriormente referenciados, bem como no banco de teses e dissertações da CAPES, quarenta e nove (49) dissertações e nove (9) teses, situadas nos seguintes campos: a) Dissertações: Educação (18), Estudos da Tradução (16), Linguística (5), Linguística Aplicada (4), Educação Especial (2), Ciências da Linguagem (1), Literatura (1), Letras (1) e Linguística, Cultura e Regionalidade (1); b) Teses: Educação (3), Semiologia (1), Literatura (1), Linguística (1), Estudos da Tradução (2) e Educação Escolar (1). 
$\mathrm{Na}$ análise dessas produções de forma cronológica, observa-se que as pesquisas nos campos da Educação e dos Estudos da Tradução e da Interpretação, em especial, as questões relacionadas à ética do tradutor e intérprete, são ainda pouco exploradas na perspectiva em que este texto se propõe a investir. Porém, há trabalhos que se destacam na discussão da ética e, entre eles, ressalta-se aqui o de Martins (2013).

Martins (2013) estabelece um diálogo sobre as práticas do tradutor e intérprete em atuação nos espaços educacionais, elaborando argumentos em torno dos olhares construídos sobre esse profissional. A partir dessa discussão, apresenta os discursos dos próprios profissionais ao analisar o código de ética dos tradutores e intérpretes e, inspirado nas teorizações dos estudos foucaultianos, problematiza sobre a ética como forma de cuidado de si e com o modo de condução que se pretende estabelecer.

Elenca uma ética parresiasta, que busca, na sua verdade, uma construção com o outro (MARTINS, 2013), uma proposta ética de vida na diferença que só é feita no embate, na ação, no movimento de ruptura, na descontinuidade que se faz na ação do pensar. A autora dispõe de ferramentas para pensar a ação do intérprete educacional "[...] que pervertem o seu papel prescrito e, na verdade do encontro com o outro, colocam-se diante do acontecimento desse ensino surdo como constituintes também de singularidades" (MARTINS, 2013, p. 217). O trabalho de Martins (2013) aproxima-se das reflexões sobre ética realizadas neste estudo, que investe em um modo de pensar sobre os espaços de atuação desse profissional para além de saberes e olhares prescritivos sobre a ética.

No que diz respeito à pesquisa, os Estudos da Tradução e da Interpretação de Línguas de Sinais se consolidam como domínio teórico ao tornarem-se um campo específico ou uma das subáreas dos Estudos da Tradução (GRBIC, 2007; VASCONCELLOS et al., 2012; RODRIGUES, 2013; SANTOS, 2013; PEREIRA, 2014).

Vale destacar, ainda, os eventos acadêmicos da área, que se configuram como manifestação e divulgação das pesquisas em nível nacional e internacional. Ocorreram quatro edições do Con- 
gresso Nacional de Pesquisas em Tradução e Interpretação de Língua Brasileira de Sinais, realizado na Universidade Federal de Santa Catarina (UFSC) em 2008, 2010, 2012 e 2014.

Ocorreu, também, o Encontro Latino-Americano de Tradutores Intérpretes e Guia-Intérpretes (ELATILS) em duas edições: a primeira na Colômbia (2009) e a segunda no Brasil (2013), sem contar as edições do Congresso Internacional da Associação Brasileira de Pesquisadores em Tradução (ABRAPT), no qual, nas duas últimas edições, contou com simpósios temáticos e conferências acerca da área da tradução e interpretação em Línguas de Sinais.

De acordo com Rodrigues (2013) e Santos (2013), esses eventos firmam, assim, a afiliação dos Estudos da Tradução e da Interpretação em Línguas de Sinais ao campo disciplinar dos Estudos da Tradução e da Interpretação em dimensão internacional.

Todavia, observa-se que a inserção de trabalhos que versam sobre a ética do tradutor e do intérprete de línguas de sinais se dá de forma tímida. E, mesmo com a ética constituindo-se como eixo temático no Congresso Nacional de Pesquisas em Tradução e Interpretação de Língua Brasileira de Sinais, somente a partir da terceira edição contou-se com trabalho com essa temática - apenas $u^{3}$ (1) - e, na quarta edição, com seis ${ }^{4}$ (6) trabalhos.

Portanto, como forma de adensar a discussão sobre ética na tradução/interpretação de Línguas de Sinais, este trabalho inscreve-se em uma perspectiva que segue para além de visão comportamental. Aqui, a ética coloca-se tanto como um modo de relacionamento do indivíduo consigo mesmo quanto como uma questão eminentemente prática (ROSA; BARCELLAR, 2014).

\section{O trabalho do tradutor e intérprete de línguas de sinais como intelectual específico e a prática de cuidado de si como um modo de vida activa}

As pesquisas supracitadas catalogadas por vários autores descrevem o conhecimento específico que se acumula no campo dos 
Estudos da Tradução e da Interpretação de Línguas de Sinais, de tal modo que justificam a sua afiliação teórica e acadêmica aos Estudos da Tradução e Interpretação de outras línguas. Tal perspectiva, considerando o lugar no qual os estudos de línguas de sinais se localizam atualmente, produz um deslocamento conceitual, político e acadêmico do intérprete, e sinaliza para a construção de seu papel a partir da emergência de uma responsabilidade com a profissão como intelectual específico que se torna.

Este texto, então, segue na abertura da caixa de Pandora ao desenvolver a discussão de uma prática de vida activa e, portanto, eminentemente política no trabalho do tradutor e intérprete de línguas de sinais, identificando-o como intelectual específico a fim de tratar de um tipo de êthos que:

\begin{abstract}
[...] alude a um modo humano de ser, sob dois aspectos: um, ao modo de como o homem, por natureza, habita a si mesmo; outro, de como o homem, valendo-se da natureza que lhe é própria, é capaz de por si mesmo reger e edificar a sua própria destinação humana. [...] o termo êthos insinua justamente o modo humano de habitar a si mesmo. (SPINELLI, 2009, p. 18).
\end{abstract}

E, a partir desse modo humano de habitar a si mesmo, este texto aposta em uma discussão atravessada pelas teorizações de inspiração foucaultiana para defender a tarefa do tradutor e intérprete de línguas de sinais como intelectual específico.

De acordo com Foucault (2005), esse sujeito, no exercício de sua tarefa, age segundo outra relação entre teoria e prática, pois atua, diretamente, sobre problemas práticos, locais. Deleuze, em conversa com Foucault (FOUCAULT, 2005, p. 69), afirma que "uma teoria é sempre local, relativa a um pequeno domínio e pode se aplicar a um outro domínio mais ou menos afastado". Foucault, em resposta, coloca: "É por isso que a teoria não expressará, não traduzirá, não aplicará uma prática; ela é uma prática. Mas local e 
regional, como você diz: não totalizadora" (FOUCAULT, 2005, p. 71). E Deleuze completa: "Uma teoria é como uma caixa de ferramentas $[. .$.$] . É preciso que sirva, é preciso que funcione"$ (FOUCAULT, 2005, p. 71).

Conforme Adorno (2004), o ponto de partida para a compreensão da tarefa política do intelectual específico fica mais clara a partir da diferença entre este e o intelectual universal. O universal é portador da verdade e da justiça, ou seja, a "verdadeira" consciência da sociedade. Essa visão de "universal" o permite distinguir o certo do errado, o verdadeiro do falso, faz com que esses intelectuais não ajam sobre questões práticas e locais, mas os mantém em um discurso generalista. Portanto, ao ser substituído pelo intelectual específico devido à sua relação com o conhecimento de um campo específico, opera com uma crítica determinada.

Então, partindo da premissa de um regime de produção das verdades, pode-se concluir que o papel desse intelectual é desestruturar o presente, já que as verdades não são universais, pois são produtos dos jogos de forças. Desestruturá-lo não a partir de uma simples crítica, "[...] mas na tenacidade em demonstrar a contingência do presente, em desestruturá-lo como resultado de um processo histórico" (ADORNO, 2004, p. 43), de tal modo que se exclui qualquer possibilidade de prever o futuro ao fixar-se no como se é hoje.

A função do intelectual, de acordo com Foucault (2006), não se resume a dizer aos outros o que deve ser feito, mas interrogar novamente os postulados, as verdades instituídas e refazer as perguntas:

Com que direito o faria? Lembrem-se de todas as profecias, injunções e programas que os intelectuais puderam formular durante os dois últimos séculos, cujos efeitos agora se vêem. O trabalho de um intelectual não é moldar a vontade política dos outros; é, através das análises que faz nos campos que são os seus, o de interrogar novamente as evidências e os postulados, sacudir os hábitos, as maneiras de fazer e de pensar, dissipar as familiaridades aceitas, retomar 
a avaliação das regras e das instituições e, a partir dessa nova problematização (na qual ele desempenha seu trabalho específico de intelectual), participar da formação de uma vontade política (na qual ele tem seu papel de cidadão para desempenhar). (FOUCAULT, 2006, p. 249).

Segundo Adorno (2014), Foucault continua a sua defesa de um posicionamento político do intelectual uma vez que afirma que um regime político é inconsistente quando indiferente à verdade e perigoso quando pretende prescrevê-la. E o intelectual, quando tem como função o "dizer verdadeiro", precisa do cuidado com essa função, pois não se trata de um dizer prescritivo, mas, sim, analítico das relações que os sistemas de pensamento vão se constituindo. O seu papel consiste em fazer a crítica, afinal, "é a partir de si que se pode fazer funcionar questões técnicas e locais que representam outros tantos pontos de vista que levam a uma visão do conjunto da sociedade e de seu funcionamento". (ADORNO, 2004, p. 46).

Nessa contemporaneidade, a partir dos dispositivos governamentais previamente descritos, a necessidade de TILS torna-se compulsória no Brasil, criando uma urgência na formação desses sujeitos e estabelecendo ações que vão na contramão dos conhecimentos produzidos na academia. Destarte, quando se tornam muitos e necessários, até que ponto a responsabilidade da tarefa como intelectual específico é assumida?

Hoje, quando os TILS se tornam "profissionais do momento" a partir da proliferação exacerbada de abertura dos concursos públicos, concomitante ao amadurecimento das discussões teóricas e acadêmicas da área, faz-se cada vez mais necessário um exercício de atitude de transformação. Afinal, atualmente, esses profissionais são requisitados e já ocupam os diversos contextos tradutórios e interpretativos, auxiliados por um conhecimento empírico ante a necessidade de uma consolidação processual da área na academia.

O status da Língua Brasileira de Sinais (Libras) como língua nacional confere ao TILS outro lugar no olhar dos dispositivos governamentais na própria discussão de sua formação e carreira. 
Isso posto, os efeitos de uma formação aligeirada para responder à urgência da ocupação desses espaços de tradução e interpretação dificulta que esses profissionais adotem a tarefa do intelectual específico (com um saber específico e político) como atitude responsiva e responsável.

Em vários cursos proferidos no Collége de France, Foucault (2010) trabalha a questão da arte de governar, analisando os sentidos e dispositivos que constituem essa arte historicamente no exercício do poder e do saber. O autor afirma que a ideia de tal arte está ligada diretamente à descoberta e ao conhecimento de uma verdade, e “[...] isso implica a constituição de um saber especializado, a formação de uma categoria de indivíduos também especializados no conhecimento dessa verdade". (FOUCAULT, 2010, p. 46).

Diante disso, Foucault (2010) alerta do risco que acontece com a composição desse saber especializado a partir de uma verdade constituída que diz respeito ao "[...] fato de um certo número de indivíduos apresentarem-se como especialistas da verdade a ser imposta à política [...]". (FOUCAULT, 2010, p. 46).

Todavia, o exercício dessa atitude como tarefa do intelectual específico, diante da política instituída, torna o sujeito TILS capaz de verdade e de transformação de si, e, assim, um agente de transformação desse quadro social. Pode-se chamar de atitude a capacidade de elaborar a sua própria subjetividade a partir da prática de veridicção desse sujeito, que não é apenas um trabalho político e moral, mas ético e estético.

De acordo com Adorno (2004), Foucault afirma que ética e política se engendram constantemente no trabalho do intelectual e, por isso, levanta questões relevantes, como “[...] qual a relação entre verdade e a crítica do trabalho do intelectual? Para que reconhecer se a crítica é autêntica e verdadeira?" (ADORNO, 2004, p. 54). Essas perguntas são necessárias para que haja um critério de veracidade da crítica política e ética exercida pelo TILS como tarefa desse intelectual.

Adorno (2004) coloca, ainda, que o intelectual deve ser capaz de se interrogar enquanto cidadão preocupado com questões espe- 
cíficas e com o efeito delas no conjunto político e social contemporâneo. Ele mesmo poderá ser o motor de análises teóricas justamente a partir de seus questionamentos pessoais. "Dito de outro modo: ele deve ser capaz de permutar sua posição de intelectual com sua posição de cidadão" (ADORNO, 2004, p. 46).

Enfim, para fazer uma prática ética, o intelectual não fica limitado à sua função política, porém, por conta da sua ligação entre a vida prática e a teoria, subjetiva-se em uma espécie de existência estética. Portanto, há um critério de inteligibilidade desse sujeito, a fim de que o intelectual não caia na armadilha dos jogos de poder quando está na luta política, dando a sua contribuição à causa com o seu conhecimento técnico.

Assim, na esteira de Adorno (2004), pode-se concluir, como critério de inteligibilidade, que o TILS:

\begin{abstract}
[...] possa dizer qualquer coisa na ordem da teoria; mas ao contrário, que é preciso ter uma atitude exigente, prudente, experimental; é necessário, a todo momento, passo a passo, confrontar o que se pensa e o que se diz com o que se faz e o que se é. [...] a chave da atitude política pessoal de um filósofo (no nosso caso TILS) não deve ser pedida de suas ideias, como se ela pudesse ser deduzida das ideias; é a sua filosofia, enquanto vida, é a sua vida filosófica, é a seu ethos. (ADORNO, 2004, p. 55).
\end{abstract}

Qual a relação que o intelectual deve estabelecer entre sua teoria e sua prática, entre vida e conhecimento? Ter-se uma atitude prudente, exigente e experimental como critério de inteligibilidade da crítica exercida desse intelectual é necessário para confrontarse o que se pensa com o que se diz, o que se faz e com o que se é - a produção da verdade e o acesso a ela é a questão primordial que atravessa a sua tarefa. Assim, propõe-se, nesse exercício de pensamento, um deslocamento do sujeito na produção da verdade no trabalho do TILS como prática de cuidado de si. 
Esse trabalho de si para consigo, elaboração de si para consigo, transformação progressiva de si para consigo em que se é o próprio responsável por um longo labor é o que nomeamos de ascese (àskesis). Trata-se de uma forma de trabalho configurado a partir de diferentes ações, exercícios e técnicas. (MARÍN-DÍAZ, 2014, p. 17).

Foucault (2006, p.14) propõe, em aula de 6 de janeiro de 1982, do curso Hermenêutica do Sujeito, um rápido sobrevoo sobre o que se deve reter, por ora, sobre a noção de epiméleia heautoû ou cuidado de si:

1. "Primeiramente o tema de uma atitude geral, um certo modo de encarar as coisas, de estar no mundo, de praticar ações, de ter relações com o outro". O cuidado de si é uma atitude para consigo, para com o outro e para com o mundo.

2. Em segundo lugar, a epiméleia heautoû é também uma forma de atenção, de olhar. Converter o olhar do exterior, dos outros, do mundo para si mesmo. Implica certa maneira de estar atento ao que se passa no pensamento.

3. E, em terceiro lugar, essa noção não é apenas uma atitude geral ou uma forma de atenção voltada para si. "Também designa sempre ações que são exercidas de si para consigo. Ações pelas quais nos assumimos, nos modificamos, nos purificamos, nos transformamos e nos transfiguramos".

Sendo assim, esses pontos levantados por Foucault (2006) são suficientes para a reflexão sobre a epimeléia hetouaû (cuidado de si) e a relação que o trabalho do tradutor e intérprete no exercício de sua tarefa como intelectual específico - ou seja, como este trabalho pode estabelecer uma relação com o saber que é inerente à profissão e, ainda, como pode afetar significativamente a relação do TILS consigo mesmo. 
Não se pode perder de vista que o labor cotidiano empreendido pelo TILS exige uma atividade intensa de elaboração linguística e social que, logo, dá margem suficiente para uma elaboração de si para consigo mesmo. Nessa linha, o trecho do texto de Benjamim, "A Rua de mão única", sobre a ação de caminhar e sobrevoar, pode dar pistas da relação que o TILS pode empreender consigo mesmo e com o texto no ato tradutório.

A força da estrada do campo é uma se alguém anda por ela, outra se sobrevoa de aeroplano. Assim é também a força de um texto, uma se alguém o lê, outra se o transcreve. Quem voa vê apenas como a estrada se insinua através da paisagem [...]. Somente quem anda pela estrada experimenta algo de seu domínio e de como, [...] ela faz sair, a seu comando, a cada uma de suas voltas, distâncias, belverdes, clareiras, perspectivas [...]. Assim comanda unicamente o texto copiado a alma daquele que está ocupado com ele, enquanto o mero leitor nunca fica conhecendo as novas perspectivas de seu interior [...] porque o leitor obedece ao movimento de seu eu no livre reino aéreo do devaneio, enquanto o copiador se faz ser comandado [...]. (BENJAMIN, 1995, p. 16).

O caminhar foi escolhido propositadamente, pois refere-se a uma ação antiga, própria do humano. Compreendendo que a vida activa é prática da própria condição humana e que o cuidado de si é uma atitude, a ação de caminhar se torna-, então, uma ótima figura de possibilidade de exercício da prática de cuidado de si no trabalho do TILS. Enfim, é por meio dessa ação que os humanos ocupam os espaços através de deslocamento/ movimento/transformação do sujeito.

De tal modo, ao cumprir o imperativo proferido no texto de Masschelein e Simons (2014), intitulado "Ponhamo-nos a caminho", pode-se, aqui, pensar a relação com o texto (como material de trabalho) empreendido pelo TILS ao tomar alguma atitude descrita por Benjamim (1995): tanto caminhar no texto quanto sobre- 
voá-lo. Essa reflexão faz-se necessária uma vez que, ao tomar o trabalho como "criador de si", é fundamental que o tradutor, como um bom artífice, olhe para o texto a ser traduzido e domine seu ofício, sabendo exatamente como "as coisas são feitas".

A diferença está na atividade em si: caminhar ou voar. Segundo Masschelein e Simons (2014), quem voa, apenas vê e domina o caminho; porém, quem caminha, o experimenta e sente o domínio e a autoridade dele sobre si. Benjamim (1995) compara: enquanto sobrevoar é ler o texto, caminhar é copiá-lo.

Ao ler o texto, o sujeito compreende-o de acordo suas próprias leis, seu próprio entendimento. Assim, o texto está sujeito à perspectiva de quem o sobrevoa e não tem poder nenhum sobre ele, não abre sua visão, não o desloca, não o atravessa. Porém, quem caminha a pé no texto, sem a perspectiva do fim - porque, se se caminha com a perspectiva do fim da caminhada, da terra prometida, corre-se o risco de não ser interpelado pelas surpresas do caminho, até mesmo vendo-as como incômodas -, tem outra relação com esse caminho (com o texto).

Benjamim (1995) então sugere que a caminhada (a cópia) abre os olhos, bem como liberta e desloca o olhar, o que não é o mesmo de oferecer um novo olhar ou uma perspectiva nova, nem mesmo "desvelar" algo possivelmente oculto. Abrir os olhos é ficar atento e expor-se. Assim, essa relação com o texto é um modo de relacionar-se com o presente e vincular-se a ele, de prestar atenção, de expor-se ao texto (MASSCHELEIN; SIMONS, 2014).

A autoridade do caminho não nos conduz à terra prometida, mas podemos dizer que nos empurra. Não nos diz aonde deveríamos ir, mas puxa-nos, fazendo-nos sair de onde estamos (nos afasta de quem somos e do que pensamos). Então, copiar o texto não é compreendê-lo ou re-apresentá-lo, mas traçar um caminho através dele. Caminhar é ao mesmo tempo, percorrer um caminho e permitir que o caminho submeta a alma. (MASSCHELEIN; SIMONS, 2014, p. 46). 
Pensando na ação de colocar-se a caminho (não no caminho, mas $a$ caminho, o que supõe movimento e não verdade instituída) como uma prática de cuidado de si na relação com os textos a traduzir, é possível que o TILS seja capaz de transformar o próprio labor em um modo de cuidado de si quando se deixa atravessar pelo texto, quando o "copia" no sentido benjaminiano e não apenas o sobrevoa. Quando se torna atento e vincula-se ao texto, permitindo, assim, que o este o interpele, o que deve ser um trabalho efetuado pelo intelectual específico como sua responsabilidade.

Entendendo que o texto existe e quando o TILS se propõe a caminhar sobre ele (copiar, na perspectiva de Benjamim; traduzir, na perspectiva de Masschelein e Simons), não é prudente adotar uma meta apenas (a terra prometida/ a técnica/ o trabalho tradutório final), mas, sim, colocar-se a caminho, arriscar a própria subjetivação, a própria alma através de uma relação diferente com o presente. Enfim, caminhar é estar presente no presente.

\section{Caminhar como prática de cuidado de si: a tríplice potência na constituição de um espaço pedagógico com o outro no ato tradutório}

Ao definir, neste trabalho, a caminhada/tradução como uma prática de cuidado de si, pode-se então perceber que essa ação produz deslocamento/ transformação/elaboração de si. Logo, é possível intuir que, a partir da atitude/ação para com o outro que nos atravessa, para o qual o texto caminhado será traduzido, é possível elaborar, com esse outro, um espaço pedagógico, nos termos de Masschelein e Simons (2014).

A perspectiva da caminhada/tradução pode criar condições de possibilidade para a constituição de um espaço pedagógico, que, segundo Masschelein e Simons (2014), se dá a partir da produção de dois componentes na relação com o outro: a potência (ou tríplice potência) e a capacidade de ex-posição. 
A primeira potência discorrida pelo autor é a do movimento ou do deslocamento para fora de si, da vontade de colocar-se constantemente a caminho para voltar constantemente para si mesmo (lembrando que caminhar supõe movimento, deslocamento). A segunda potência é a da palavra, isto é, a potência da tradução ou inteligência. Não de apenas suspender o véu sob o qual as coisas estão ocultas, mas a potência da tradução que confronta um falante com outro falante. E, por fim, a potência do pensamento ou da reminiscência, ou seja, "recordar a um sujeito pensante seu destino" (MASSCHELEIN; SIMONS, 2014, p. 35).

Essa tríplice potência, então, desdobra-se na capacidade de ex -posição, outra característica do sujeito que habita o espaço pedagógico. Essa ex-posição remete ao ser de palavras que se é como humano. Significa que, mais do que falantes, uma palavra humana foi endereçada a alguém e, assim, como humano, esse ser está condenado a responder. Ademais, um ser de palavra está exposto a outros e às palavras dos outros, é um ser exposto aos outros (e às suas palavras).

Enfim, cria-se um espaço pedagógico por meio do labor tradutório produzido pela caminhada no texto, e essa prática de cuidado de si (a caminhada) faz emergir a tríplice potência e ex-posição no outro que, ao receber o texto traduzido, é, portanto, convocado a se vincular ao presente e a pôr-se a caminho com o tradutor.

A tarefa do tradutor, segundo Benjamin (2010, p. 217), “[...] consiste em encontrar na língua para a qual se traduz a intenção a partir da qual o eco do original é nela despertado". O autor ainda defende que, diferentemente da intenção do escritor, que é ingênua, primeira e intuitiva, a do tradutor é derivada, última e ideativa. Assim, o tradutor, em sua tarefa, aliará a liberdade e a fidelidade.

Se, tradicionalmente, essas noções são consideradas tendências opostas, Benjamin (2014) restitui a possibilidade de reconciliação delas quando confere, à língua da tradução, o dever de "[...] desprender-se, para fazer ecoar sua própria espécie de intentio enquanto harmonia, complemento da língua na qual se comunica, e 
não sua intentio enquanto reprodução de sentidos" (BENJAMIN, 2014, p. 221).

Por isso, o maior elogio a uma tradução, sobretudo na época de seu aparecimento, não é poder ser lida como se fosse um original em sua língua. Antes, a significação dessa fidelidade, garantida pela literalidade, é precisamente esta: que o grande anelo por uma complementação entre línguas se expresse na obra. (BENJAMIN, 2014, p. 223).

Admitindo a perspectiva benjaminiana sobre a tradução, a possibilidade de caminhar sobre o texto pode ser um modo de o TILS assumir, de forma responsiva e responsável, a tarefa do tradutor. Afinal, ao transformar-se, como intelectual específico que é, em um ser de palavra, endereça-a a alguém, produzindo, através do ato tradutório, nesse outro, a tríplice potência e a capacidade de ex-posição.

Tal tarefa condena o sujeito a quem a palavra foi endereçada a responder e a se ex-por com sua própria palavra. Essa prática é eminentemente ética e política, já que ambas são condições para a tarefa do intelectual. A partir da percepção de que o trabalho do TILS pode ser muito mais do que empírico, adota-se, assim, a posição de intelectual nas ações de si para consigo e, consequentemente, nas ações de si para com o outro e para com o mundo.

Ao tomar a ação de caminhar a fim de produzir a tríplice potência (movimento/palavra/pensamento), torna-o capaz de ex-posição na luta de transformação do quadro social e político contemporâneo, quadro esse no qual emergem, cada vez mais, as formações aligeiradas e incompletas, compactuando com a perpetuação do lugar atualmente ocupado por esse profissional diante dos dispositivos governamentais.

Quando verdades e tomadas de posição políticas são exercidas como atitude, faz-se necessário aplicar os critérios supracitados para verificar sua veracidade e autenticidade: Quem diz? O que diz é feito? Qual a relação entre sua posição política, a sua crítica e a 
sua vida enquanto TILS? Ora, quando um TILS assume sua tarefa de intelectual específico na sua posição política calcado na ética, não temerá as consequências dela e sobreviverá aos critérios de veridicção em que sua crítica será submetida.

Adorno (2004), na esteira de Foucault, afirma que, no modelo grego (socrático), o sujeito capaz de verdade é um sujeito moralmente ético. Não é um problema para os gregos o questionamento "do que" se diz, mas "quem" o diz. Nesse modelo parrhesiasta, não parece haver problemas com a aquisição da verdade, porque o sujeito é moralmente aceito para ter a verdade consigo - o falante faz uso da sua liberdade e opta por falar francamente em vez de persuadir pela verdade.

\begin{abstract}
O parresiasta é alguém que, quando diz a verdade, se expõe a risco: é sua coragem que se mostra em sua ação de dizer a verdade. Além do mais, a enunciação da verdade é sempre a enunciação de uma crítica que parte da base e visa a um poder. (ADORNO, 2004, p. 60).
\end{abstract}

Diante do exposto, pensar uma atitude ética é assumir que o intelectual específico deve ser um sujeito capaz de verdade - ser um parresiasta, ou seja, passar pelos critérios descritos expostos, qual sejam, a resposta ativa e a relação entre o dizer e o fazer. É um sujeito capaz de produzir esse efeito quando elabora sua própria subjetividade enquanto tradutor a partir das práticas de cuidado de si.

\title{
Considerações finais
}

A ação de abrir a caixa de Pandora e expor a discussão atual sobre a questão ética que permeia o trabalho do TILS como prática de cuidado de si se constitui em ir aos "porões", aos fundamentos do trabalho desse profissional, a fim de pensar as políticas que permeiam essa prática. Pandora não é mais tão assustadora, todavia, 
é impossível prever os riscos quando há a ex-posição do conteúdo de sua caixa.

Retomando a proposta deste texto, que é de discorrer sobre outras possibilidades de pensar o trabalho do TILS, vale ressaltar o argumento de Santos (2013) quando este afirma que, para criar políticas, se faz necessário recorrer às pesquisas a fim de pensá-las e problematizá-las. Este texto propôs pensar as políticas e práticas de tradução e interpretação, recorrendo, também, à discussão sobre a ética como prática de cuidado de si no trabalho desse profissional.

Ao assumir, de forma responsiva e responsável, a tarefa do tradutor, esse profissional evoca seu papel como intelectual específico e põe-se a caminho no texto, produzindo um espaço pedagógico como efeito da capacidade de potência e de ex-posição.

Com o intuito de produzir, no espaço da tradução e da interpretação, uma postura radicalmente aberta e franca, faz-se cada vez mais necessário um exercício de atitude de transformação, pelo fato do TILS ser requisitado e ocupar os diversos contextos tradutórios e interpretativos auxiliado por um conhecimento empírico ante a necessidade de uma consolidação processual da área na academia. Muitas ações e deliberações acerca do trabalho TILS são reafirmadas por meio dos dispositivos governamentais, por exemplo, formação e carreira, descaracterizando a tarefa do intelectual específico (com um saber ético e político) como atitude responsiva e responsável.

Ter-se uma atitude prudente, exigente e experimental é necessário para confrontar-se o que se pensa com o que se diz, o que se faz e com o que se é, e o TILS, como intelectual, deve estabelecer uma relação entre sua teoria e sua prática de vida exercida como um êthos.

Assim, nas considerações finais deste texto (não da discussão), é relevante identificar, neste exercício do pensamento, as condições de possibilidades de constituição de outros olhares e saberes sobre a formação do TILS como intelectual específico, relacionada à dimensão ética e política assumida como tarefa no exercício profissional. 


\section{Notas}

4. O mapa mencionado no trabalho encontra-se na seguinte referência: HATIM, B.; MUNDAY, Jeremy. Translation: an advanced resource book. New York: Routledge, 2004. p. 8. Disponível em: < http://staff.uny.ac.id/sites/default/files/ pendidikan/Donald \%20Jupply, \%20S.S., \%20M.Hum/Reference \%20Book \% 20 2-Translation\%20An\%20advanced \%20resource\%20book.pdf > . Acesso em: 30 ago. 2015.

5. Pandora foi enviada a Epimeteu, irmão de Prometeu, como um presente de Zeus. Prometeu, antes de ser condenado, a ficar 30 mil anos acorrentado no Monte Cáucaso, tendo seu fígado comido pelo abutre Éton todos os dias. Alertou o irmão quanto ao perigo de aceitar presentes de Zeus. Epimeteu, no entanto, ignorou a advertência do irmão e aceitou o presente do rei dos deuses, tomando Pandora como esposa. Pandora trouxe uma caixa (uma jarra ou ânfora, de acordo com diferentes traduções), enviada por Zeus em sua bagagem. Epimeteu acabou abrindo a caixa e liberando os males que haveriam de afligir a humanidade dali em diante: a velhice, o trabalho, a doença, a loucura, a mentira e a paixão. No fundo da caixa, restou a Esperança (ou, segundo algumas interpretações, a Crença irracional ou Credulidade). Com os males liberados da caixa, teve fim a idade de ouro da humanidade. Disponível em : < http://www.sohistoria.com.br/ef2/ mitologiagrega/p1.php- $>$. Acesso em: 29 jun. 2015.

6. SUZANA, E.R.B. Tradutores/Intérpretes da Língua de Sinais: A ética em questão.

7. MARTINS, V. R. O. Atuação do intérprete de língua de sinais em contexto de ensino: algumas contribuições sobre a relação de mestria. ROSA, A. S.; BACELLAR, M. I. M. Ética e a atuação do intérprete de libras/português em contexto de saúde mental. CARNEIRO, B. G.; ROCHA, N. N. Intérprete de libras educacional: o papel de educador e a ética. SILVA, I. S. A. F.; PÊGO, C.F. O panorama do preconceito linguístico e suas contribuições para a perspectiva ética do profissional TILS. FRAZÃO, E.; SANTOS, S. F. Os impactos iniciais da disciplina de ética ministrada aos intérpretes de língua de sinais em formação. DANTAS, A. L. S. Tradução ética e da letra de um artigo científico do português para libras. 


\section{Referências}

ADORNO, F. P. A tarefa do intelectual: o modelo socrático. In GRÓS, F. Foucault: A coragem da verdade. Tradução de Marcos Marcionilo. São Paulo: Parábola editorial, 2004.

Anais do Congresso Nacional de Pesquisas em Tradução e Interpretação de Libras e Língua Portuguesa, Universidade Federal de Santa Catarina (UFSC). III Congresso Nacional de Pesquisas em Tradução e Interpretação de Libras e Lingua Portuguesa. 2012. Disponível em: <http://www.congressotils.com.br/anais. html\#apresentacao > . Acesso em: 26 set. 2015.

. IV Congresso Nacional de Pesquisas em Tradução e Interpretação de Libras e Língua Portuguesa. 2014. Disponível em: < http://www. congressotils.com.br/anais.html\#apresentacao >. Acesso em: 26 set. 2015. ARENDT, H. A condição humana. 12. ed. rev. Tradução de Roberto Raposo. Rio de Janeiro: Forense universitária. 2014.

. O que é política? 11. ed. Tradução de Reinaldo Guarany. Rio de Janeiro: Bertrand Brasil, 2013.

BENJAMIN, W. A tarefa do tradutor. In WERNER, Heiderman (Org). Clássicos da teoria da tradução. 2 ed. Tradução de Susana Kampff Lages. Florianópolis: UFSC, 2010.

. Obras escolhidas II: rua de mão única. 5. ed. Tradução de Rubens Rodrigues. São Paulo: Editora Brasiliense, 1995.

FOUCAULT, M. A hermenêutica do sujeito. 2. ed. Tradução de Márcio Alves da Fonseca e Salma Tannus Muchail. São Paulo: Martins Fontes, 2006.

. Conversando com Michel Foucault. In Ditos e Escritos VI: Repensar a política. Organização e seleção de textos de Manoel de Barros da Motta. Tradução de Ana Lúcia Paranhos Pessoa. Rio de Janeiro: Forense Universitária, 2010.

. Microfisica do poder. 21. ed. Tradução de Roberto Machado. Rio de Janeiro: Edições Graal. 2005. 
GRBIC, N. Where do we come from? What are we? Where are we going? A bibliometrical analysis of writings and research on sign language interpreting. The Sign Language Translator \& Interpreter, v.1, n.1. p.15-51, 2007.

HATIM, B.; MUNDAY, Jeremy. Translation: an advanced resource book. New York: Routledge, 2004. p. 8. Disponível em: <http://staff.uny.ac.id/sites/default/files/pendidikan/Donald \%20Jupply, \%20S.S., \%20M.Hum/Reference $\% 20$ Book\%202-Translation\%20An\%20advanced\%20resource\%20book.pdf $>$. Acesso em: 30 ago. 2015.

MARÍN-DÍAZ, D. L. Autoajuda, educação e práticas de si: genealogia de uma antropotécnica. Belo Horizonte: Autentica editora, 2015.

MARTINS, V. R. de O. Posição-mestre: desdobramentos foucaultianos sobre a relação de ensino do intérprete de língua de sinais educacional. 2013. Tese (Doutorado em Educação) - Universidade Estadual de Campinas.

MASSCHELEIN, J.; SIMONS, M. Ponhamo-nos a caminho. In MASSCHELEIN, J.; SIMONS, M. A pedagogia, a democracia e a escola. Belo Horizonte: Autêntica, 2014.

PEREIRA, M. C. P. Produções acadêmicas sobre interpretação de língua de sinais: dissertações e teses como vestígios históricos. Cadernos de Tradução (UFSC), v. 1, p. 99-117, 2010.

RODRIGUES, C. H. A interpretação para a língua de sinais brasileira: efeitos de modalidade e processos inferenciais. 2013. Tese (Doutorado em Estudos Linguísticos) - Universidade Federal de Minas Gerais.

ROSA, A. S; BACELLAR, M. I. M. Ética e a atuação do intérprete de libras/ português em contexto de saúde mental. Anais do Congresso Nacional de Pesquisas em Tradução e Interpretação de Libras e Língua Portuguesa, Universidade Federal de Santa Catarina (UFSC). IV Congresso Nacional de Pesquisas em Tradução e Interpretação de Libras e Língua Portuguesa. 2014. Disponível em: <http:// www.congressotils.com.br/anais.html\#apresentacao > . Acesso em: 26 set. 2015. SANTOS, S. A. A tradução/interpretação de língua de sinais no Brasil: uma análise das teses e dissertações de 1990 a 2010. Tese (Doutorado em Programa de Pós-Graduação em Estudos da Tradução)-Universidade Federal de Santa Catarina. 2013. 
SENNETT, R. $O$ artífice. 4. ed. Tradução de Clóvis Marques. Rio de Janeiro: Record, 2013.

SPINELLI. M. Sobre as diferenças entre éthos com epsílon e êthos com eta. Trans/Form/Ação. 2. n. 32. p. 9-44. São Paulo: Programa de Pós-Graduação em Filosofia da Universidade Estadual Paulista Julio de Mesquita, 2009.

VASCONCELLOS, M. L. et al. Mapping Libras Interpretation Research in the Context of Translation Studies. In: QUADROS, R. M.; FLEETWOOD, E.; METZGER, M. Signed Language Interpreting in Brazil. Washington D.C.: Gallaudet University Press, 2012. p. 3-20.

Recebido em: 29/05/2015

Aceito em: 28/09/2015 